\title{
An Approach to Calculate Leakage Flow, Stiffness and Damping of Annular Seals in Turbulent Flow Using Lubrication Theory, Part II: Results
}

\author{
Satyam Shivam Gautam ${ }^{1)}$ and Mihir Kumar Ghosh $^{2)^{*}}$ \\ ${ }^{1)}$ Mechanical Engineering Department, North Eastern Regional Institute of Science and Technology \\ Itanagar, Arunachal Pradesh - 791 109, India \\ ${ }^{2)}$ Mechanical Engineering Department, Institute of Technology, Banaras Hindu University \\ Varanasi - 221005 , India \\ *Corresponding author: mkghosh47@gmail.com
}

( Manuscript received 22 June 2007; accepted 18 September 2007; published 31 October 2007 )

\begin{abstract}
This paper is in continuation of its part I. It presents the rotordynamic behavior of a circular seal and multilobe seal for various $L / D$ ratio, taper ratio and eccentricity ratio in the turbulent flow regime considering the effect of fluid inertia. The paper has been focused particularly on the leakage flow, stiffness and damping coefficients of a plain and a taper annular seals. Rotordynamic coefficients have been evaluated for various seal configurations for water as the working fluid.
\end{abstract}

Keywords: turbulent lubrication, leakage flow, stiffness, damping, taper seal, multilobe seal

\section{Introduction}

Annular seals are installed in turbo machinery to limit the leakage of fluid between adjacent regions at different pressures. The main purpose of annular seals is to control leakage flow. With the over increasing demand for higher speeds, pressures and temperatures in high performance rotating machinery, non-contacting sealing is essential for long and reliable operation. Apart from the minimal leakage the fluid film in the annulus region generates considerable stiffness and damping. It is well known that annular seals can generate significant forces when the working fluid is a liquid.

Black et al. ${ }^{1)}$ have explained the influence of seal forces on the rotordynamic behavior of pumps. These pioneering efforts brought into attention the actual nature of seal flows as dramatically different from conventional circular journal bearing flow phenomena. Light viscosity liquids, large axial pressure gradients, and large clearance to radius ratio determine the flow in annular seals to be turbulent. Furthermore, the flow character and the dynamic seal force response are greatly influenced by the development of the circumferential flow velocity ${ }^{2}$.

A number of publications by Childs et al. ${ }^{3,4,5)}$ reveal the influence of seal forces on the rotordynamic behavior of pumps. Childs and Dressman ${ }^{4)}$ have developed an analytical computational method to calculate pressure field and dynamic coefficients for tapered high pressure annular seals typical of neck ring and interstage seals employed in multistage centrifugal pumps.

Marquette, Childs and San Andres ${ }^{5}$ have presented leakage and rotordynamic coefficients of a plain annular seal at centered and eccentric positions. The influence on rotordynamic coefficients of pressure drop, running speed and static eccentricity was investigated. This paper presents the results of rotordynamic behavior viz. leakage flow, stiffness and damping coefficients of a circular, taper and multilobe seals in the turbulent flow regime including fluid inertia effects.

\section{Film Thickness Expressions}

$$
\begin{array}{lr}
\bar{h}=1+\varepsilon \cos \theta & \text { [Parallel circular seal] } \\
\bar{h}=1+\varepsilon \cos \theta+z \frac{\Delta C}{C} \quad \text { [Tapered circular seal] } \\
\text { where, } \Delta C=\left(C_{i}-C\right) / L \\
\bar{h}=\frac{h}{C}=\frac{1}{\delta}-\left(X_{j}+X-X_{L}^{i}\right) \cos \theta-\left(Y_{j}+Y-Y_{L}^{i}\right) \sin \theta
\end{array}
$$

[Parallel multilobe seal]

\section{Comparisons of Results with Available Literature:}

Table 1:

a: Water seal [Childs and Dressman, 4]

$D=0.0798 \quad \mathrm{~m}, \quad L=0.0432 \mathrm{~m}, \quad C=2.967 \times 10^{-4} \mathrm{~m}$, $\mathrm{RPM}=3,600, \quad \rho=1000 \quad \mathrm{~kg} / \mathrm{m}^{3}, \quad \mu=1.245 \times 10^{-3} \quad \mathrm{~Pa}-\mathrm{s}$, $\Delta p=1.035 \times 10^{6} \mathrm{~Pa}, C_{i}=C, \xi=0.0$

\begin{tabular}{|l|c|c|}
\hline & $K_{x x} \times 10^{-6}(\mathrm{~N} / \mathrm{m})$ & $D_{x x}(\mathrm{Ns} / \mathrm{m})$ \\
\hline Childs et al. & 2.614 & 9,837 \\
\hline Present Analysis & 2.591 & 6,876 \\
\hline
\end{tabular}


b: Water seal [Childs, 3]

$D=0.0798 \quad \mathrm{~m}, \quad L=0.0432 \mathrm{~m}, \quad C=2.967 \times 10^{-4} \mathrm{~m}$ $R P M=3,600, \quad \rho=1000 \quad \mathrm{~kg} / \mathrm{m}^{3}, \quad \mu=1.295 \times 10^{-3} \quad$ Pa-s, $\Delta p=1.035 \times 10^{6} \mathrm{~Pa}, C_{i}=C, \xi=-0.5$

\begin{tabular}{|l|c|c|}
\hline & $K_{x x} \times 10^{-6}(\mathrm{~N} / \mathrm{m})$ & $D_{x x}(\mathrm{Ns} / \mathrm{m})$ \\
\hline Childs & 2.889 & 10,860 \\
\hline Present Analysis & 3.241 & 8,599 \\
\hline
\end{tabular}

c: High pressure fuel turbo pump (HPFTP) [Childs, 3] $D=0.0798 \quad \mathrm{~m}, \quad L=0.0432 \mathrm{~m}, \quad C=1.397 \times 10^{-4} \mathrm{~m}$, $R P M=37,360, \quad \rho=70.78 \quad \mathrm{~kg} / \mathrm{m}^{3,}, \mu=1.16 \times 10^{-5} \quad$ Pa-s, $\Delta p=1.492 \times 10^{7} \mathrm{~Pa}, C_{i}=C, \xi=0.0$

\begin{tabular}{|l|c|r|}
\hline & $K_{x x} \times 10^{-8}(\mathrm{~N} / \mathrm{m})$ & $D_{x x}(\mathrm{Ns} / \mathrm{m})$ \\
\hline Childs & 0.902 & 22,540 \\
\hline Present Analysis & 1.001 & 25,667 \\
\hline
\end{tabular}

Table 2: Leakage flow, direct stiffness and direct damping comparisons to marquette et al. [5] for water seal

$D=0.07629 \mathrm{~m}, L=0.03493 \mathrm{~m}, C=1.1 \times 10^{-4} \mathrm{~m}, \rho=1000$ $\mathrm{kg} / \mathrm{m}^{3,}, \mu=1.245 \times 10^{-3} \mathrm{~Pa}-\mathrm{s}, C_{i}=C$, Speed(RPM)

Table 2(a):

Leakage flow ' $Q$ ' (lit/s), $\Delta p=4.14 \mathrm{MPa}, \xi=0.1$

(Present calculations)

\begin{tabular}{|c|l|l|l|l|l|}
\hline RPM & $\varepsilon=0.0$ & $\varepsilon=0.1$ & $\varepsilon=0.2$ & $\varepsilon=0.3$ & $\varepsilon=0.4$ \\
\hline 10,200 & 1.16 & 1.16 & 1.18 & 1.21 & 1.25 \\
\hline 17,400 & 0.80 & 0.80 & 0.81 & 0.82 & 0.84 \\
\hline 24,600 & 0.63 & 0.64 & 0.64 & 0.64 & 0.64 \\
\hline
\end{tabular}

(Marquette et. al.)

\begin{tabular}{|c|l|l|l|l|l|}
\hline RPM & $\varepsilon=0.0$ & $\varepsilon=0.1$ & $\varepsilon=0.2$ & $\varepsilon=0.3$ & $\varepsilon=0.4$ \\
\hline 10,200 & 0.83 & 0.83 & 0.84 & 0.85 & 0.86 \\
\hline 17,400 & 0.74 & 0.74 & 0.75 & 0.76 & 0.77 \\
\hline 24,600 & 0.65 & 0.66 & 0.67 & 0.68 & 0.68 \\
\hline
\end{tabular}

Table 2(b):

Direct stiffness ' $K_{x x}{ }^{\prime}(\mathrm{MN} / \mathrm{m}), \Delta p=4.14 \mathrm{MPa}, \xi=0.1$

(Present calculations)

\begin{tabular}{|c|c|c|c|c|c|}
\hline RPM & $\varepsilon=0.0$ & $\varepsilon=0.1$ & $\varepsilon=0.2$ & $\varepsilon=0.3$ & $\varepsilon=0.4$ \\
\hline 10,200 & 19.31 & 17.97 & 17.25 & 17.26 & 18.12 \\
\hline 17,400 & 21.05 & 20.29 & 20.16 & 20.62 & 21.81 \\
\hline 24,600 & 24.07 & 23.33 & 23.38 & 24.06 & 24.86 \\
\hline
\end{tabular}

(Marquette et. al.)

\begin{tabular}{|c|c|c|c|c|c|}
\hline RPM & $\varepsilon=0.0$ & $\varepsilon=0.1$ & $\varepsilon=0.2$ & $\varepsilon=0.3$ & $\varepsilon=0.4$ \\
\hline 10,200 & 19.30 & 19.30 & 19.0 & 18.90 & 18.80 \\
\hline 17,400 & 19.0 & 19.10 & 19.20 & 19.20 & 19.20 \\
\hline 24,600 & 19.10 & 19.20 & 19.30 & 19.40 & 19.50 \\
\hline
\end{tabular}

Table 2(c):

Direct damping ' $D_{x x}{ }^{\prime}(\mathrm{kNs} / \mathrm{m}), \Delta p=4.14 \mathrm{MPa}, \xi=0.1$

(Present calculations)

\begin{tabular}{|c|c|c|c|c|c|}
\hline RPM & $\varepsilon=0.0$ & $\varepsilon=0.1$ & $\varepsilon=0.2$ & $\varepsilon=0.3$ & $\varepsilon=0.4$ \\
\hline 10,200 & 18.11 & 16.85 & 16.19 & 16.19 & 17.00 \\
\hline 17,400 & 11.59 & 11.17 & 11.10 & 11.36 & 12.01 \\
\hline 24,600 & 9.40 & 9.10 & 9.12 & 9.39 & 9.03 \\
\hline
\end{tabular}

(Marquette et. al.)

\begin{tabular}{|c|c|c|c|c|c|}
\hline RPM & $\varepsilon=0.0$ & $\varepsilon=0.1$ & $\varepsilon=0.2$ & $\varepsilon=0.3$ & $\varepsilon=0.4$ \\
\hline 10,200 & 19.55 & 19.85 & 20.10 & 20.40 & 20.50 \\
\hline 17,400 & 22.10 & 22.20 & 22.80 & 23.40 & 24.00 \\
\hline 24,600 & 24.20 & 24.40 & 25.60 & 26.30 & 28.20 \\
\hline
\end{tabular}

Some of the results of the present investigation are compared with the theoretical results of Childs ${ }^{3)}$ and Childs and Dressman ${ }^{4}$ as shown in table 1 for parallel circular seal. Results have been presented for both low as well as high speed seals. Comparisons with low speed water seal have been presented in part ' $a$ ' and ' $b$ ' of table 1 for different entrance loss coefficients. In part 'c' HPFTP high speed seal results have been compared with the results reported by $\mathrm{Childs}^{3)}$. The results of rotordynamic coefficients viz. direct stiffness and direct damping are in reasonably good agreement with the results of Childs and Childs and Dressman.

Marquette et al. ${ }^{5)}$ presented theoretical and experimental results of the leakage flow rate and rotor dynamic coefficients of high pressure plain annular seals of short length i.e. $L / D=0.45$ under eccentric operation. Pressure drop across the seal was $4.14 \mathrm{MPa}$. Results were taken for three speeds of the journal as shown in tables 2(a) - 2(c).

From the results of leakage flow rate, it is observed that the present calculations lead to somewhat higher estimation of leakage flow at lower speed of $10200 \mathrm{rpm}$ whereas at higher speed of $24600 \mathrm{rpm}$ the present results of leakage flow rates are reasonably close to the results of Marquette et al. Comparisons of rotordynamic coefficients i.e. direct stiffness and direct damping with the results of Marquette et al. have been shown in table 2. Direct stiffness results are reasonably close to Marquette et al. for all eccentricity ratios. Direct damping shows reasonably close agreement with the results of Marquette et al. at lower journal speed whereas at higher journal speed discrepancies occur.

\section{Discussion}

To show the effect of various parameters viz. $L / D$ ratio, taper ratio and eccentricity ratio the lubricant used in present calculations is water having a density of 1000 $\mathrm{kg} / \mathrm{m}^{3}$, absolute viscosity of $0.001245 \mathrm{~Pa}-\mathrm{s}$ and radial exit clearance $C=0.0002967 \mathrm{~m}$, diameter of journal $D=0.0798 \mathrm{~m}$. The pressure drop across the seal is 1.035 $\mathrm{MPa}$. The circular seal geometry is shown in Figs. 1-3 in part I of this paper. 


\subsection{Effect of $\mathrm{L} / \mathrm{D}$ ratio}

Results of rotordynamic coefficients vs. rotor speed for various $L / D$ ratios are presented in Figs. 1 - 3. Fig. 1 shows the leakage flow vs. speed for various $L / D$ ratios. It is seen that leakage flow reduces with increase in speed. Leakage flow also decreases with increase in $L / D$ ratio which is an expected trend and is a result towards the better seal performance. However, for short seal with $L / D=0.5$ it is seen that leakage flow decreases very marginally with increase in rotor speed. Besides, the leakage flow is also lower than the leakage flow of higher $L / D$ ratios at low rotor speeds. Thus, the prediction of leakage for very short seals at lower Reynolds numbers may not conform to the general trend observed at higher $L / D$ ratios.Fig.2 shows the variation of direct stiffness vs. speed for various $L / D$ ratios. It is seen that direct stiffness increases with increase in speed for any particular value of $L / D$ ratio. It is also seen that direct stiffness increases as the $L / D$ ratio increases. Fig. 3 shows the variation of damping coefficients with speed for various $L / D$ ratios. In the figure, it is seen that direct damping coefficient decreases with increase in speed. However, damping coefficients increase with increase in $L / D$ ratio which is also likely to improve the stability of the seal.

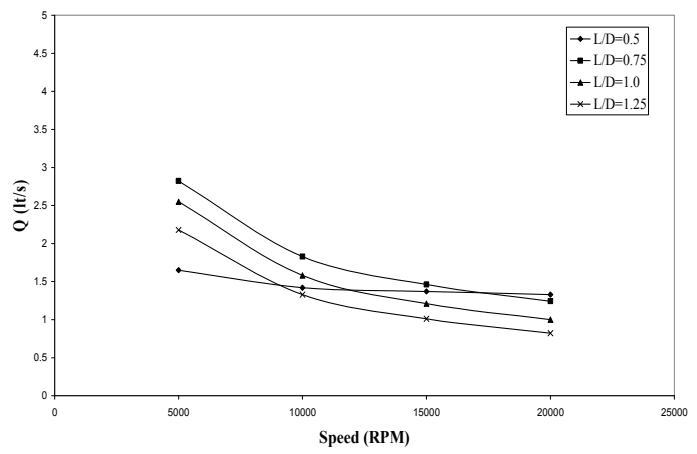

Fig.1: Leakage flow vs. speed for various $L / D$ ratio, $\gamma=1, \varepsilon=0.0, p_{\text {in }}=1.135 \mathrm{MPa}$

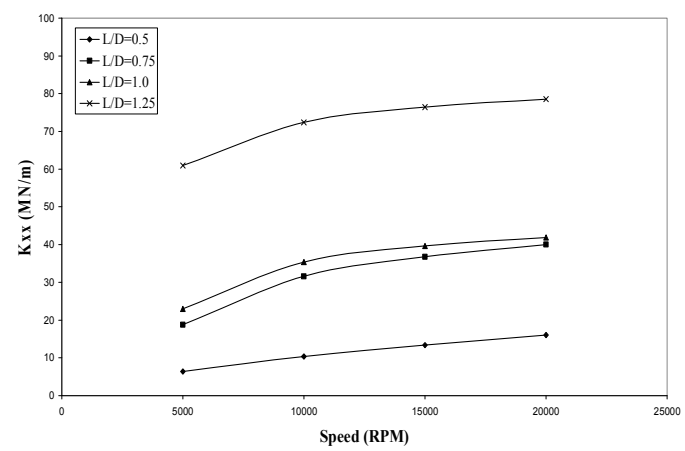

Fig.2: Direct stiffness vs. speed for various $L / D$ ratio, $\gamma=1, \varepsilon=0.0, p_{\text {in }}=1.135 \mathrm{MPa}$

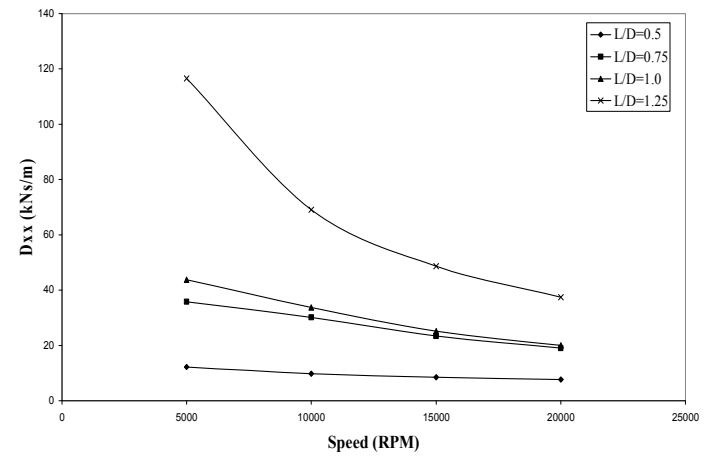

Fig.3: Direct damping vs. speed for various $L / D$ ratio, $\gamma=1, \varepsilon=0.0, p_{i n}=1.135 \mathrm{MPa}$

\subsection{Effect of taper ratio}

Results of rotordynamic coefficients vs. rotor speed for various taper ratios are presented in Figs. 4 - 6. The leakage flow reduces with increase in speed but increases with increase in taper ratios as shown in Fig.4. Similar trend is seen in the literature. Variation of stiffness and damping with speed for various taper ratios is shown in Figs. 5-6 respectively. Below approximately $10,000 \mathrm{rpm}$ both stiffness and damping are observed to decrease with taper ratio whereas beyond this speed stiffness and damping increase with taper ratio. Stiffness increases with speed. However, damping shows increase with speed below 10,000 rpm whereas above this speed damping decreases with increase in speed. Both flow field and pressure gradient are influenced by taper ratio and speed which in turn influence the stiffness and damping ratio. Beyond a certain speed its effect becomes more significant and changes the damping characteristics.

\subsection{Effect of eccentric operation}

Figs.7-9 shows the effect of eccentricity ratio and speed on leakage flow and rotordynamic coefficients. Fig.7 shows the plot of leakage flow vs. speed for various eccentricity ratios. It is observed that leakage flow decreases with increase in speed for all eccentricity ratios. But it also shows that the leakage flow decreases with increase in eccentricity ratio. It is seen that direct stiffness increases with increase in speed for all eccentricity ratios. Direct stiffness marginally increases with increase in eccentricity ratio. Direct damping is found to decrease with increase in speed for various eccentricity ratios. Direct damping is higher for higher values of eccentricity ratios. 


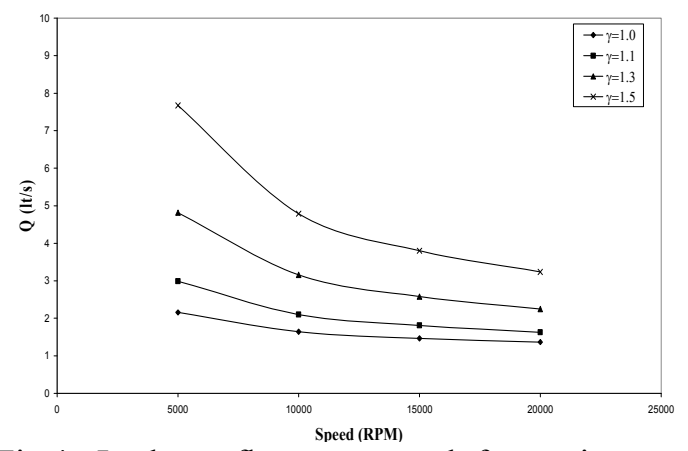

Fig.4: Leakage flow vs. speed for various $\gamma, \varepsilon=0.0$, $p_{\text {in }}=1.135 \mathrm{MPa}, L / D=0.54$

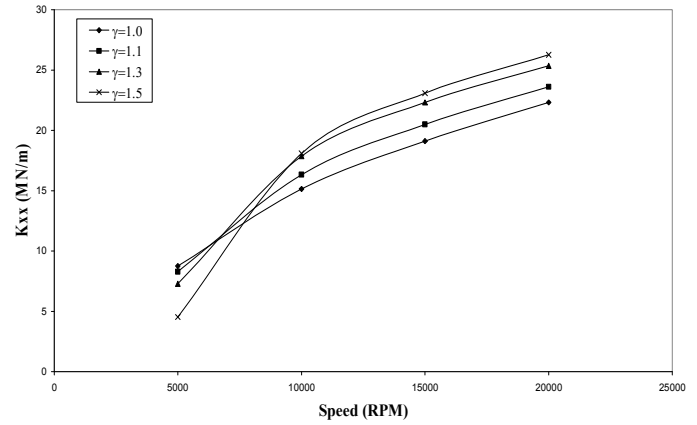

Fig.5: Direct stiffness vs. speed for various $\gamma, \varepsilon=0.0$, $p_{\text {in }}=1.135 \mathrm{MPa}, L / D=0.54$

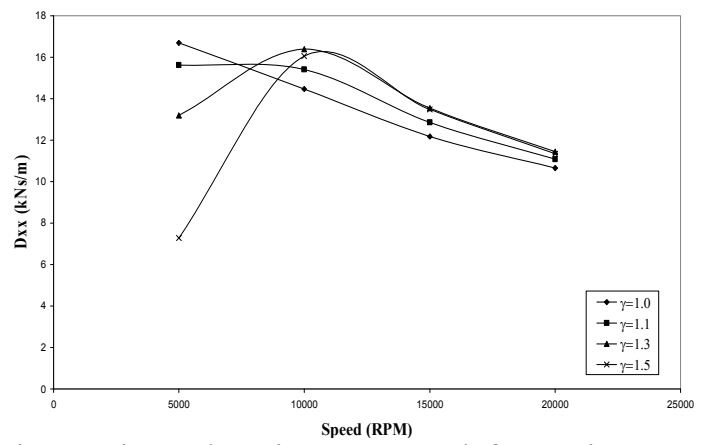

Fig.6: Direct damping vs. speed for various $\gamma, \varepsilon=0.0$, $p_{\text {in }}=1.135 \mathrm{MPa}, L / D=0.54$

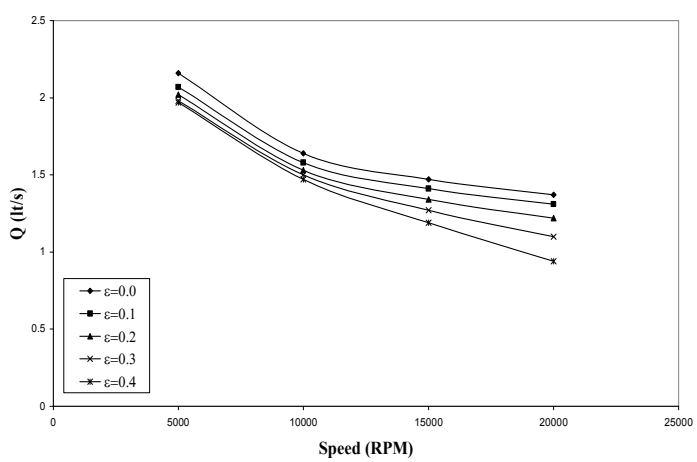

Fig.7: Leakage flow vs. speed for various $\varepsilon$, $\gamma=0.0, p_{\text {in }}=1.135 \mathrm{MPa}, L / D=0.54$

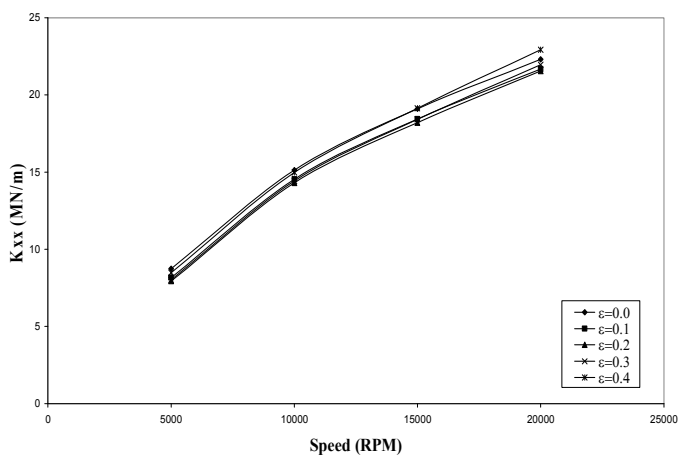

Fig.8: Direct stiffness vs. speed for various $\varepsilon$, $\gamma=0.0, p_{\text {in }}=1.135 \mathrm{MPa}, L / D=0.54$

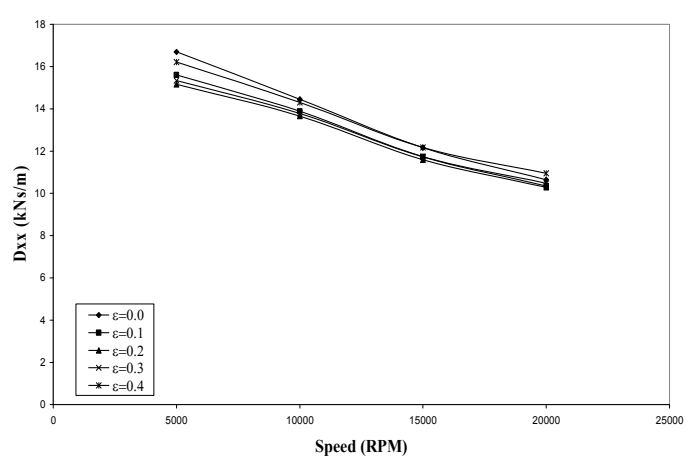

Fig.9: Direct damping vs. speed for various $\varepsilon$, $\gamma=0.0, p_{\text {in }}=1.135 \mathrm{MPa}, L / D=0.54$

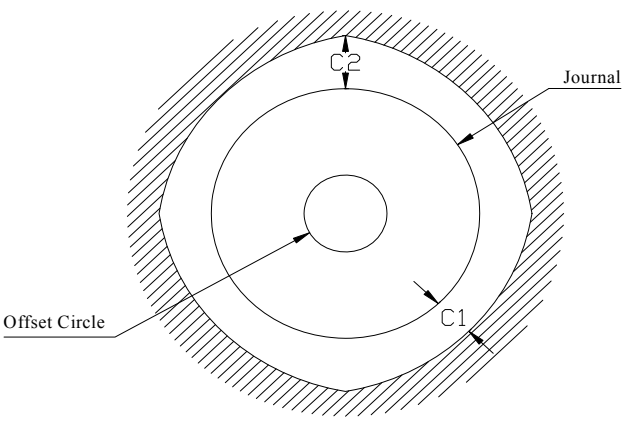

Fig. 10.1: $\quad(\delta<1)$

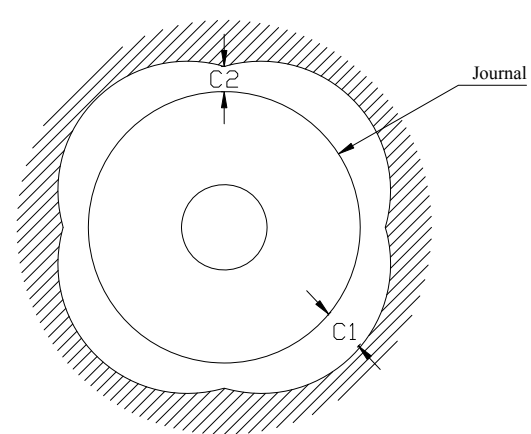

Fig. 10.2: $(\delta>1)$

Multi lobe seal geometry 


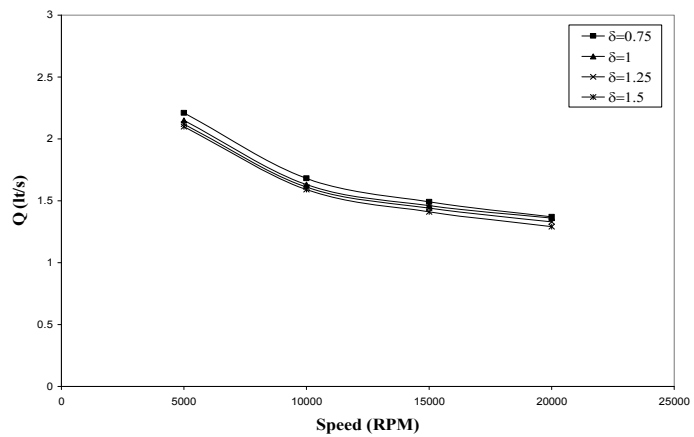

Fig.11: Leakage flow vs. speed for various $\delta, \gamma=1, \varepsilon=0.0$, $p_{i n}=1.135 \mathrm{MPa}, L / D=0.54$

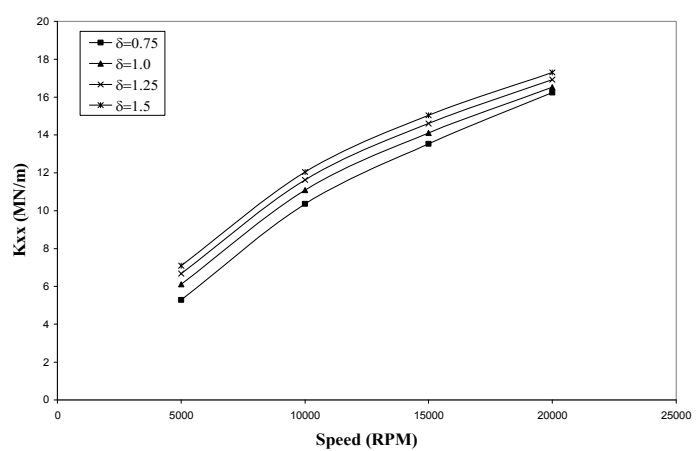

Fig.12: Direct stiffness vs. speed for various $\delta, \gamma=1$, $\varepsilon=0.0, p_{\text {in }}=1.135 \mathrm{MPa}, L / D=0.54$

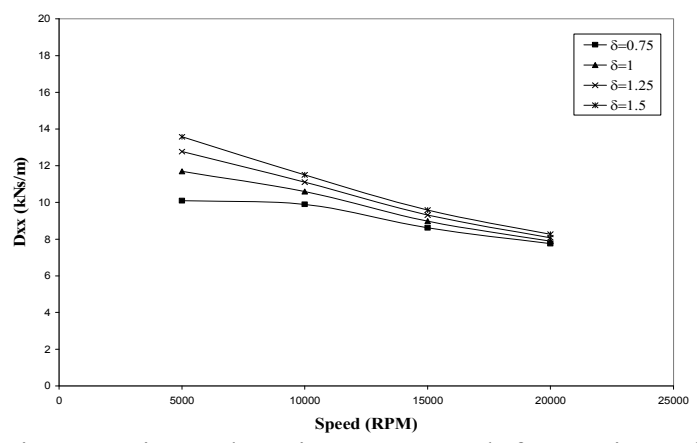

Fig.13: Direct damping vs. speed for various $\delta, \gamma=1$, $\varepsilon=0.0, p_{i n}=1.135 \mathrm{MPa}, L / D=0.54$

\subsection{Effect of multilobe seal geometry}

The multilobe seal geometry is shown in Fig.10. The results of the performance of multilobe seals in terms of leakage flow and rotor dynamic behavior are presented for parallel seal concentric operation through Figs. 11 13. The leakage flow vs. speed for various $\delta$ has been shown in Fig.11. It is observed that leakage flow reduces as the offset factor increases for all the operating speeds. Fig. 12 shows the variation of direct stiffness vs. speed for various offset factors. Direct stiffness increases with increase in speed for a particular offset factor. Whereas for a given speed it increases with increase in the offset factor and thus maximum stiffness is observed for offset factor of 1.5. Thus in order to obtain better results with respect to direct stiffness, $\delta>1$ geometry should be used.
As the rotational speed increases hydrodynamic effect become significant and is seen to offset the high axial flow component due to increased rotational flow component. This results in increase in direct stiffness with rotor speed. Fig. 13 shows the variation of damping coefficients with speed for various $\delta$ parameters. In the figure it is seen that the damping coefficients decrease with increase in speed. However, direct stiffness increases with increase in $\delta$.

Increase in direct stiffness and damping coefficients have stabilizing effect. It is seen that as speed increases the direct stiffness increases with increase in $\delta$ factors. The magnitude of direct stiffness is much larger. Direct damping remains higher for $\delta$ equals 1.5 with increase in speed. Thus, for a given rotor mass, stability limits would be determined by the rotordynamic coefficients and direct stiffness and damping would play a vital role to stabilize the rotor.

Table 3(a): Direct stiffness, $K_{x x}(\mathrm{MN} / \mathrm{m})$ vs speed for various eccentricity ratios

\begin{tabular}{|c|c|c|c|c|c|}
\hline RPM & $\varepsilon=0.0$ & $\varepsilon=0.1$ & $\varepsilon=0.2$ & $\varepsilon=0.3$ & $\varepsilon=0.4$ \\
\hline 5000 & 8.74 & 8.17 & 7.94 & 8.03 & 8.48 \\
\hline 10000 & 15.14 & 14.54 & 14.31 & 14.44 & 14.98 \\
\hline 15000 & 19.11 & 18.44 & 18.22 & 18.43 & 19.14 \\
\hline 20000 & 22.31 & 21.68 & 21.56 & 21.95 & 22.94 \\
\hline
\end{tabular}

Table 3(b): Direct stiffness, $K_{y y}(\mathrm{MN} / \mathrm{m})$ vs speed for various eccentricity ratios

\begin{tabular}{|c|c|c|c|c|c|}
\hline RPM & $\varepsilon=0.0$ & $\varepsilon=0.1$ & $\varepsilon=0.2$ & $\varepsilon=0.3$ & $\varepsilon=0.4$ \\
\hline 5000 & 8.74 & 8.09 & 7.63 & 7.33 & 7.20 \\
\hline 10000 & 15.13 & 14.45 & 13.98 & 13.69 & 13.59 \\
\hline 15000 & 19.11 & 18.35 & 17.86 & 17.62 & 17.64 \\
\hline 20000 & 22.30 & 21.58 & 21.17 & 21.06 & 21.30 \\
\hline
\end{tabular}

Table 3(c): Direct damping, $D_{x x}(\mathrm{kNs} / \mathrm{m})$ vs speed for various eccentricity ratios

\begin{tabular}{|c|c|c|c|c|c|}
\hline RPM & $\varepsilon=0.0$ & $\varepsilon=0.1$ & $\varepsilon=0.2$ & $\varepsilon=0.3$ & $\varepsilon=0.4$ \\
\hline 5000 & 16.69 & 15.61 & 15.16 & 15.34 & 16.21 \\
\hline 10000 & 14.46 & 13.88 & 13.66 & 13.79 & 14.30 \\
\hline 15000 & 12.17 & 11.74 & 11.60 & 11.73 & 12.18 \\
\hline 20000 & 10.65 & 10.35 & 10.29 & 10.48 & 10.95 \\
\hline
\end{tabular}

Table 3(d): Direct damping, $D_{y y}(\mathrm{kNs} / \mathrm{m})$ vs speed for various eccentricity ratios

\begin{tabular}{|c|c|c|c|c|c|}
\hline RPM & $\varepsilon=0.0$ & $\varepsilon=0.1$ & $\varepsilon=0.2$ & $\varepsilon=0.3$ & $\varepsilon=0.4$ \\
\hline 5000 & 16.69 & 15.46 & 14.58 & 14.01 & 13.75 \\
\hline 10000 & 14.45 & 13.80 & 13.35 & 13.07 & 12.97 \\
\hline 15000 & 12.16 & 11.68 & 11.37 & 11.22 & 11.23 \\
\hline 20000 & 10.65 & 10.30 & 10.11 & 10.06 & 10.17 \\
\hline
\end{tabular}


Table 4: Comparison of results between laminar and turbulent flow conditions

\begin{tabular}{|c|c|c|c|c|}
\hline RPM & \multicolumn{2}{|c|}{$\begin{array}{c}K_{x x}(\mathrm{MN} / \mathrm{m}) \\
\text { Lam. } \\
\text { Tur. }\end{array}$} & \multicolumn{2}{c|}{$\begin{array}{c}D_{x x}(\mathrm{kNs} / \mathrm{m}) \\
\text { Lam. } \\
\text { Tur. }\end{array}$} \\
\hline 5000 & 8.64 & 6.41 & 16.51 & 12.25 \\
\hline 10000 & 8.58 & 10.34 & 8.20 & 9.88 \\
\hline 15000 & 8.45 & 13.38 & 5.38 & 8.52 \\
\hline 20000 & 8.24 & 16.06 & 3.93 & 7.67 \\
\hline
\end{tabular}

Tables 3(a) - 3(d) show the data of direct stiffness $\left(K_{x x}, K_{y y}\right)$ and direct damping $\left(D_{x x}, D_{y y}\right)$ for various eccentricity ratios. The variations between $K_{x x} \& K_{y y}$ and $D_{x x} \& D_{y y}$ are clearly seen in the tables at higher eccentricities due to hydrodynamic effect. The effect of turbulent flow as compared to laminar flow has been presented in table 4 .

\section{Summary}

Seal parameters viz. rotor speed, $L / D$ ratio, taper ratio and seal geometry influence the leakage flow, stiffness and damping of the seal. Leakage flow reduces with increase in speed, eccentricity ratio and $L / D$ ratio. However, it increases with increase in taper ratio. Stiffness increases with increase in speed whereas damping reduces at higher speed. Whereas both stiffness and damping increase with increase in $L / D$ ratio and taper ratio. Higher $L / D$ ratio and a moderate taper would thus result in better performance for the annular seals. The stabilizing effect of multilobe geometry can be exploited to improve the stability of the seal. Multilobe geometry with $\delta>1$ may be useful in this context.

\section{References}

[1] Black, H. F. and Jenssen, D. N., "Dynamic Hybrid
Properties of Annular Pressure Seals," Proc. J. Mech. Eng., 184, 1970, 92-100.

[2] Black, H. F., "Research Notes on Journal Bearings with High Axial Flows in the Turbulent Regime," J. Mechanical Engineering Science, 12, 4, 1970, 301-303.

[3] Childs, D. W., "Dynamic Analysis of Turbulent Annular Seals Based on Hirs Lubrication Equation," Trans. ASME, J. Lubrication Technology, 105, 1983, 437-445.

[4] Childs, D. W. and Dressman, J. B., Convergent-Tapered Annular Seals: Analysis and Testing for Rotordynamic Coefficients," Trans. ASME, J. Tribology, 107, 1985, 307-317.

[5] Marquette, C.R., Childs, D.W. and San Andres, L.A., "Eccentricity Effects on the Rotor Dynamic Coefficients of Plain Annular Seals," Trans. ASME, J. Tribology, 119, 1997, 443-449.

\section{Nomenclature}

$C \quad$ Radial clearance at the seal exit (m)

$C_{i} \quad$ Radial clearance at the seal entrance (m)

$E \quad$ Eccentricity $(\mathrm{m}), \quad \varepsilon=e / C$ (dimensionless)

$H \quad$ Film thickness, $\bar{h}=h / C$

$X, Y$ Time-dependent dimensionless perturbation co-ordinates of the journal center measured from its equilibrium position

$X_{j}, Y_{j}$ Dimensionless equilibrium co-ordinates of the journal center

$X_{L}^{i}, Y_{L}^{i} \quad$ Dimensionless lobe center co-ordinates $(i=1,2$, $3,4)$

$\delta \quad$ Offset factor $\left(C_{1} / C_{2}\right)$ as in Fig. 10 .

$\gamma \quad$ Taper ratio $\left(C / C_{i}\right)$

$\xi \quad$ Entrance loss coefficient 